\title{
Cutaneous Melanoma cM0 TNM Finding v8
}

National Cancer Institute

\section{Source}

National Cancer Institute. Cutaneous Melanoma cMO TNM Finding v8. NCI Thesaurus.

Code C136895.

Cutaneous melanoma without evidence of distant metastasis. LDH level is not applicable. (from AJCC 8th Ed.) 